\title{
Conceptualization of Knowledge to Develop Thinking Process - A Novel Way of Teaching and Learning
}

\author{
Tongpil Min \\ PonderEd Education, Canada
}

\begin{abstract}
Learning and teaching knowledge cannot develop thinking process because simple understand to know is all that needs. Thinking process in this paper means a series of systematic steps of thinking. It involves observation to datarize what was observed, description of the observation, questions based on the description, analysis of description and questions to build hypothesis. This systematic thinking process is also referred as conceptualization of knowledge. The conceptualization of knowledge is learning and teaching method with thinking process. It does not focus on knowing knowledge by understanding. Knowledge must be gone through a series of systematic thinking process so that it can be conceptualized. Once knowledge is conceptualized, it can be used, modified, utilized to discover new phenomena, to develop or to invent new tools, and even can be applied to create new concepts such as artificial satellite and general relativity theory. In other words, conceptualization of knowledge is foundation of creative thinking. Since it is systematic thinking process, it can be added to any type of learning and teaching methods. By utilizing this method in learning and teaching the efficiency of study and learning outcomes will increase significantly. In addition, the future of students' life will be also changed because the same study method can be applied to their future life. Please note that the term 'datarize' is used to distinguish from data collection from research.
\end{abstract}

\section{Introduction}

Conceptualization of knowledge is a novel learning and teaching methods that processes knowledge by systematic thinking process. Learning knowledge by understanding does not directly train students to develop thinking process because the process involved are the copy and paste of the knowledge from one to another. For example, when a person learns that apple is a fruit, the knowledge does not have to go through the students' thinking process. Students can simply accept to know with understanding. This is the easiest and fastest way of delivering information. In this way, students can learn knowledge without hard work since everything is ready for them to understand to know. On the other hand, educators, however, must work hard to prepare the knowledge for students to understand to know. In other words, students are customers and educators are service providers. Students receive final products such as ready to eat meals and educators are the cooks and servers. In education sector, this was the most widely accepted teaching methods. Because ideally, educators can deliver broad range of knowledge in short period of time with this method. However, this story is unrealistic. Students are suffering from digesting the knowledge that they are learning. If two chapters dealt in one hour lecture, time for students to spend to grasp the concept outside the classroom could take double or triple of the lecture. Only a few students could get benefit out of this approach. In addition, getting ready to eat meals are not what students are coming to classes. They are looking for chances to learn to be professional cooks rather than customers.

To overcome the problems in classrooms, various teaching and learning strategies have been developed such as experience-based learning [1] [2] [3], projectbased learning [4], problem-based and inquiry learning [5] etc. Each strategy has its' own strength. However, all these methods are branches of experience-based learning since students must be part of the activities. For example, for students to learn from a project, students must carry out the project. It is understandable since if a person would like to learn how to cook, the person should start cooking to learn. Cooking students means that students learn to cook by experiences. This makes education highly effective. However, these methods also have a few disadvantages. The first issue is with the time. Learning by experiences takes time. New knowledge accumulates faster as science, technologies, and society evolve. As seen during COVID-19, online education tools have evolved fast to bridge home to schools. IT departments had to work hard to develop and apply the tools, instructors and staffs had to learn to use the new tools, and students also had to adapt to the online environment. Considering that many different sectors are advancing and releasing new knowledge every moment, educations must catch up with the new knowledge and deliver to the students so that they can use the knowledge at work in the future. Thus, experience-based education is not effective for dealing with amount of knowledge.

The second challenge is with students' interests. If education is specialized in a specific field such as culinary academy, all students would actively engage in classes. Other than cases like these, not all students 
would be interested in the topics dealt in classes. Students might not engage proactively.

The third issue is with plagiarism. This applies to project-based teaching and learning or similar teaching strategies. The intention of these approaches is for students to develop projects by themselves. However, many students search for answers from references or internet rather than finding the answers by themselves. A project is to develop or discover something new or unknown. It requires thinking process. When students were given a chance to use their own thinking process to develop a project, majority of students would search for answers rather than developing one. Searching answers from known sources might be fast and easy to achieve the goal. Only problem is that the achievement is based on copy and paste of other people's work. Thus, this method rarely contributes development of students' thinking process as intended.

All the issues in learning and teaching strategies are from one critical piece that is missing in common - thinking process. If thinking process is combined with these methods, students' learning outcomes will increase significantly.

What if students can learn (build) new knowledge by themselves outside the classroom by extending the classroom learning?

What if students can learn knowledge as if they experience in classroom?

What if students can learn to use their thinking process to develop project instead of searching for answers?

\section{What if students can learn how to learn?}

The learning and teaching method of conceptualization of knowledge were developed based on thinking process.

\section{Conceptualization of Knowledge is Foundation of Creative Thinking}

Conceptualization of knowledge is a method for students to develop thinking process. It is the foundation of creative thinking that was discussed in chapter 8 of 'Education Policy and Leadership' volume 1 book [6].

Creative thinking is the thinking process to discover new phenomena, to develop or invent new tools, and to create new concepts. As seen from human history, these are known to be genius' thinking process and unknown until now. If the systematic process of thinking to create something new has been known, many geniuses should be recorded in the history. However, as history proves, only a limited number of people were able to provoke the thinking process. Because the process is not observable, it has not been neither learnable nor teachable. For the first time of human history, the thinking process was revealed by Min [6]. In this book, Min addressed the types of creative thinking processes and how to develop creative thinking processes. The creative thinking was categorized in three types based on thinking processes and they are leveled so that creative thinking can be developed systematically.

In brief, the first level is the thinking process to discover new phenomena. The example was about a bird in the winter. People look at birds in the winter but rarely ask curiosity questions like 'A bird's legs are not insulated with feathers, but they are standing on ice and snow. What mechanisms are there to prevent their legs from being frozen?' If answer to the questions is discovered and it was unknown before, this discovery would be recognized as one of the extraordinary discoveries.

The second level of creative thinking process is to invent or develop new tools. An example for this thinking process was Steve Jobs' fonts. As Jobs addressed in 2005 Sandford university graduation speech [7], he started the development of fonts by connecting two dots which were typography and computer. Science and technology were able to advance due to this thinking process. Such thinking processes can also be seen from history. By mimicking bird wings, airplane developed. Combining stone, vine, and a wood stick, stone hammer was invented. Likewise, all the historical developments were led by the creative thinking process that can invent or develop new tools.

The highest level of the creative thinking process discussed in the book [6] is to create new concepts. Artificial satellite was drawn by simulating relative relationship among force, travel distance, and mass of an object. General relativity theory was created by simulating the relative relationship among speed of light, space, and time. It was not possible for educators to teach students to develop these thinking processes systematically. The reason is that the thinking process is not visible to follow. This is what the conceptualization of knowledge is about. It literally visualizes the thinking process step by step so that students can see the process to follow. By conceptualizing knowledge, students can develop creative thinking process systematically.

\section{Meaning of Conceptualization of Knowledge}

Knowledge and concepts are not the same. Knowledge refers knowing something by understanding. For example, snow can be known to people who have never seen in real life but from movies or SNS. However, the feeling when snow melts on hands and faces, the differences in formability of snowballs, or other characteristics of 
snow cannot be easily understandable. As mentioned previously, experiences are one of the most effective ways of learning these characteristics. Basically, experience is process of realization. The difference between realization and conceptualization, however, is from reasoning. One can realize that the different types of snow have different characteristics. However, unless the characteristics are processed to provide answers to any curiosity questions like 'what would be the factors that make different characteristics of snow?' In other words, conceptualization of knowledge is a thinking process that processes knowledge with reasoning.

\section{Systematic Thinking process to Conceptualize Knowledge}

Thinking process needs to be modified depending on types of subjects. If it is an article, terminologies used in the articles should be the primary targets to begin with. Since the most of learning and teaching methods start with data, step by step thinking process using data from textbook will be explained using mushroom as an example.

In general, knowledge-focused teaching delivers knowledge as follows:

"Fungi absorb food after digesting it outside their bodies" [8].

This statement is from a biology textbook and teaching materials (prepared PowerPoint slide from the publisher).

Knowledge-focused teaching delivers such knowledge either plainly or with some modification. Some educators increase teaching efficiency by connecting the knowledge to real-life cases such as mushroom. For example,

Do you eat mushroom. Did you know that mushroom is fungi?

Did you know that fungi digest food by releasing chemicals and enzymes externally and absorb the digested food?'

The above question will prompt some students to be interested. Once students are interested in the topic, teaching knowledge will be successful. However, this type of approaches does not include thinking process for students to develop. Because students do not need to use their thinking process to learn the knowledge.

To teach students to develop thinking process, the thinking process should be visualized step by step so that students can observe to follow. Thus, instead of delivering knowledge either by plain way or in connection to real life, the knowledge should be conceptualized by step by step thinking process. The conceptualization of knowledge starts from datarization of data. Then the datarized elements undergoes systematic process to be conceptualized. The overall process are as follows:

i. Observe to datarize and to describe.

ii. Questions based on the description.

iii. Preparation for analysis (comparison, experiments, observation etc.).

iv. Analysis to hypothesize.

The term 'datarize' is used in this research study to distinguish 'data collection' as in research. Since learning and teaching is using the data that is already provided by researchers, the term 'datarize' refers a process of extracting elements from given data.

\subsection{Observe to Datarize and to Describe}

The data that are being used as an example in this paper is pine mushrooms (Figure 1) that are growing in some mountains in British Columbia, Canada. This is the data that will be used for conceptualization of knowledge process onward.

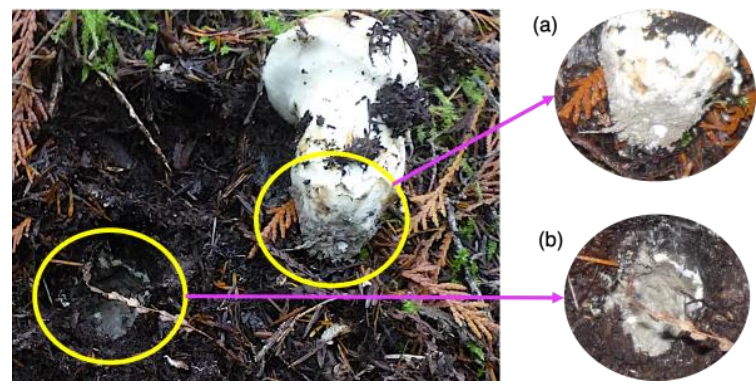

Figure 1. Freshly pulled pine mushroom

(a) Hyphae with (hair like structure) covered with grey and dry soil.

(b) The hole made after the mushroom picked. The soil around the hole where hyphae was is also grey and dry.

The 'Observe to datarize and to describe' can be separated into two steps. The first is observe to datarize and next is description of the observation. Observe to datarize is to extract elements from the data. Elements mean that breakdown of the components into each component. The data can be broken down into background and mushroom as well as places where mushroom was growing. Mushroom can also be divided by body and the hyphae which is compatible to root and shoot of a plant. Once the data is divided into each element, the information from 
observe to datarize can be described to be processed as follows:

i. The hyphae are covered with dry and grey soil.

ii. Soil of the hole where mushroom was picked is also dry and grey.

iii. The surrounding soil except the place where hyphae was is dark and wet including around body of the mushroom.

When teaching with the above method, students might not be able to know what to do or where to observe from the first place. Then, providing focus area as shown in circles in the figure could help.

\subsection{Questions based on description}

Question is considered one of the most important factors in education sector. Especially questions that triggers curiosity are essential components for inquiry-based learning [9]. The curiosity questions also considered as one of the key factors in creative thinking processes [6]. However, finding answers to curiosity questions are challenging especially when answer is not known to the world yet. With questions like 'how could a bird's legs are not frozen without insulation?', if an educator knows the answer, the teaching process can be straightforward. However, if answers to the questions are not known, an educator might be struggling to handle. In addition, as Min discussed in building concepts [10] and connecting concepts books [11], not all types of questions can be used for thinking process development. On the same principle, the questions at this step are also specific but relatively simpler compared to the questions for creative thinking [6]. The questions should be based on the descriptions from the observation. One of the simplest ways to make questions are turning descriptions into questions by adding 'why' or 'how'. Here are example questions from the descriptions from previous step:

Why are hyphae covered with dry and grey soil?

Why is the soil of the hole also dry and grey?

Why is the surrounding soil dark and wet including the soil around the mushroom body?

As mentioned above, the questions that triggers students' curiosity are effective for teaching. However, this approach might not be effective for students to develop thinking process unless it is the students who ask the curiosity questions. Reasons to turn the description into questions are two folds. First is that to train students to ask curiosity questions so that the same skill can be applied in creative thinking process later. Second is that these questions promote brain to continue the thinking process to prepare the datarized elements for further analysis.

\subsection{Preparation of datarized elements for analysis}

Observe to datarize and description of observation are the steps to visualize what was observed. In other words, these are the processes of making connection between visual data to language. Since the thinking process is to identify the cause and reasons of observed data (e.g., grey soil around hyphae of a mushroom), the datarized elements need to be prepared for analysis to find reasoning behind.

For analysis, the description and questions must be categorized by similarity and differences to compare. Categorizing datarized elements for comparison or other means of processes such as experiments is preanalysis step. It is the step preparing the data for analysis. For example, to answer to the question of the bird's legs in the winter, dissection of a bird legs can be done as an experiment. The dissection and observation from the dissection must be followed by analysis of what was observed to find answers. Thus, organization of similarity and differences from the elements observed need to be compared for analysis to find answers. With the questions from previous step, the descriptions from section 4.1 can be categorized as shown in table 1 .

Table 1. Descriptions categorized by similarity and differences

\begin{tabular}{|c|c|c|}
\hline & $\begin{array}{c}\text { Dry and grey } \\
\text { soil }\end{array}$ & $\begin{array}{c}\text { Wet and dark } \\
\text { soil }\end{array}$ \\
\hline Pine mushroom & Hyphae & Body \\
\hline $\begin{array}{c}\text { Soils surround } \\
\text { pine mushroom }\end{array}$ & Nearby hyphae & $\begin{array}{c}\text { All other } \\
\text { surrounding }\end{array}$ \\
\hline
\end{tabular}

Once the elements are categorized, summary of the similarity and differences, then questions based on the summary should be followed by:

\section{Example of summary}

The grey and dry soil is only observed near hyphae. The soils of all other parts including body of the mushroom are dark and wet.

\section{Example of questions}

Why is the soil around hyphae only grey and dry?

The questions are like ignitions of an engine. It will spark for the brain to continue the thinking process. 


\subsection{Analysis with causation-based questions}

Once datarized elements are categorized and summarized, the conceptualization of knowledge can continue with the questions based on the summary. As mentioned, the question sparks thinking process. However, this type of curiosity questions also hardly used to continue the thinking process. Because it is challenging to find answer to the curiosity questions at this stage because the datarized elements are not fully analyzed yet. Analysis to find answer requires changes in the questions to continue the thinking process. These questions are named as 'causationbased questions' and play key function in thinking process including crosscheck to confirm if thinking process is on the right track [10]. From the comparison, the soil around hyphae is only grey and dry. Causation-base questions are the questions asking the cause of the phenomena. The phenomenon in this example is differences of soil characteristics. To identify the cause, questions need to be generated to find the cause as follows:

Should the soil be dry and grey for the pine mushrooms to grow?

Is it the growth of the pine mushroom that changed characteristics of soil?

The above causation-based questions will force the brain to look at the descriptions from different angles so that the thinking process can move forward to build hypothesis.

\subsection{Building hypothesis}

Building hypothesis is one of the skills required to predict the future [12] logically. With the causationbased questions, the datarized elements can be analyzed further with thinking process to build hypothesis. Hypothesis is explanation of possible cause based on evidence and reasoning. Thus, it is the skills to predict unknown and undefined future.

Once causation-based questions asked, thinking process can move forward to analysis of datarized elements. For example, if it is the grey and dry soil that provides environment for the pine mushroom to grow, the probability for pine mushroom spores to find grey and dry soil would be very low since dry and grey soil found only small area. In addition, the grey and dry soil is only around hyphae of the mushroom. Thus, hypothesis could be - it might be the growth of the pine mushroom that changed physical characteristics of the soil. Once the hypothesis is set, research to confirm the hypothesis can be carried out. For example, collecting pine mushroom spores and planting them in dark and wet soil to observe if the growth of the mushroom can change the characteristics of the soil.

\subsection{Expending concepts further}

Conceptualization of knowledge is the process of building knowledge. Instead of simply learning and teaching knowledge, students will be able to grasp the concepts of the knowledge. With the knowledge about fungi digesting food externally, some students could have difficulties to connect and apply to mushroom even if they know mushrooms are fungi. This is because students cannot experience how mushroom digestive system works unless they do research (experience). With the topics like mushroom, neither experiences nor realization cannot be expected in common classroom. Due to this gap, students' learning outcomes are not increasing compared to the efforts that educators put.

Conceptualization of knowledge, on the other hand, trains students to process data with their own brains. Since students are the one datarizing data, students will be the one who build concepts. As they can build concepts from new knowledge by themselves, they will become independent learners.

\section{Impacts on learning and teaching}

Conceptualization of knowledge works for both learning and teaching. Many students struggle to study because 1 . There is no clear reason to study; 2 . They do not know what to do with knowledge other than memorizing; and 3. They do not know how to study. The process of conceptualization of knowledge provides solutions for all these issues and more. Also, it is the foundation of creative thinking. The thinking methods for creative thinking are directly connected to the future skills that they need [6]. Thus, students will be motivated since the same thinking process can be directly applied for their future.

In addition to the motivation, students will be able learn how to handle knew knowledge. Students spend many hours to digest learning materials (new knowledge). This means that many of them were not fully understood the concepts of learning materials. The conceptualization of knowledge is thinking process. This means that any subject can be dealt with this method. Thus, students can gradually learn how to deal with new knowledge and eventually independent as they leave their institutes.

The conceptualization of knowledge is for students to build skills of 'learn how to learn'. It can be applied for knowledge, research, future prediction and many more. Thus, this method should be considered for all types of educational institutes.

\section{References}

[1] Marsick, V. (1990), "Experience-based Learning: Executive Learning outside the Classroom", Journal of Management Development, Vol. 9 No. 4, pp. 50-60. 
[2] Andresen, L., Boud, D., and Cohen, R. (2000) Understanding Adult Education and Training $2^{\text {nd }}$ Edition: Ch 14. Experience- based learning, Routledge.

[3] Coulson, D. and Harvey, M. (2013) 'Scaffolding student reflection for experience-based learning: a framework', Teaching in Higher Education, pp 401-413.

[4] Krajcik J. S. and Blumenfeld P. C. (2006) The Cambridge Handbook of the Learning Sciences: Ch 19. Project-based learning. Academia pp 317- 333.

[5] Hmelo-silver, C. E., Duncan, R. G. and Chinn, C. A. (2007) Scaffolding and Achievement in Problem-Based and Inquiry Learning: A Response to Kirschner, Sweller, and Clark (2006), Educational Psychologist Volume (42), Issue (2), pp 99-107.

[6] Min, T. (2021) Education Policy and Leadership Volume 1: Ch 8. Teaching creative thinking: The teaching method that can bridge the education to the future! Infonomics Society.

[7] Jobs, S. (2005) Steve Jobs' 2005 Stanford Commencement Address, Stanford University YouTube channel; https://www.youtube.com/watch?v=UF8uR6Z6 K Lc. (Access Date: 2 November 2021).

[8] Taylor M. R., Simson, E. J., Dickey J. L., Hogan, K., and Reece, J. B. (2017) Biology Concepts and Connections $9^{\text {th }}$ Edition; Ch 17. Section 12. Diversity of Fungi, Pearson.

[9] von Renesse, C. and Ecke, V. (2016) Teaching Inquiry with a lens toward curiosity, Primus Volume (27), Issue (1), pp 148-164.

[10] Min, T. (2019) Thought Process-Based Education book series \#2: Level 1-1 Building concepts, PonderEd. https://w ww.PonderEd.ca ((Access Date: 2 November 2020).

[11] Min, T. (2020) Thought Process-Based Education book series \#3: Level 1-2 Connecting concepts, PonderEd. https: //www.PonderEd.ca (Access Date: 2 November 2020).

[12] Min, T. (2020) Goal-oriented Teaching Method - The Way of Maintaining the Quality of Education for Both Online and F2F, International Journal for Infonomics Volume (13), issue (2), pp 2013-2017. 